\title{
A comprehensive study of indole catalytic hydrodenitrogenation under hydrothermal conditions
}

\author{
$\mathrm{Xu} \mathrm{Liu}{ }^{1}$, Yang $\mathrm{Guo}^{1}$, Haoran $\mathrm{He}^{1}$, and Lingzhao Kong ${ }^{2}$ \\ ${ }^{1}$ Affiliation not available \\ ${ }^{2}$ SARI,CAS
}

July 13, 2021

\begin{abstract}
This article focuses on the catalytic hydrodenitrogenation (HDN) mechanism of indole under hydrothermal conditions. Both gaseous hydrogen and liquid hydrogen donor formic acid (FA) can improve indole conversion and total yield of denitrogenated products. $\mathrm{Ru} / \mathrm{C}$ showed the highest activity among the catalysts for indole conversion in all temperature conditions with the existence of $\mathrm{H} 2$ and $91.17 \%$ indole was converted at $400{ }^{\circ} \mathrm{C}$ and $60 \mathrm{~min}$. Based on reaction kinetic experiments, a kinetic model was developed to describe the hydrothermal HDN reaction of indole over the home-made Ni80Ru20/ $\gamma-\mathrm{Al} 2 \mathrm{O} 3 \mathrm{catalyst}$, which clearly captured all data trends and fitted the temporal variation of all major liquid products. High activation energy for formation of O-containing substance o-cresol from both mathematical fitting and density functional theory (DFT) calculation indicated a rare occurrence of reaction between pyrrole ring-opening product methyl aniline and $\mathrm{H} 2 \mathrm{O}$, consistent with experimental observation that only a trace of o-cresol was detected.
\end{abstract}

\section{Hosted file}

Main Document.docx available at https://authorea.com/users/425441/articles/530271-acomprehensive-study-of-indole-catalytic-hydrodenitrogenation-under-hydrothermalconditions 